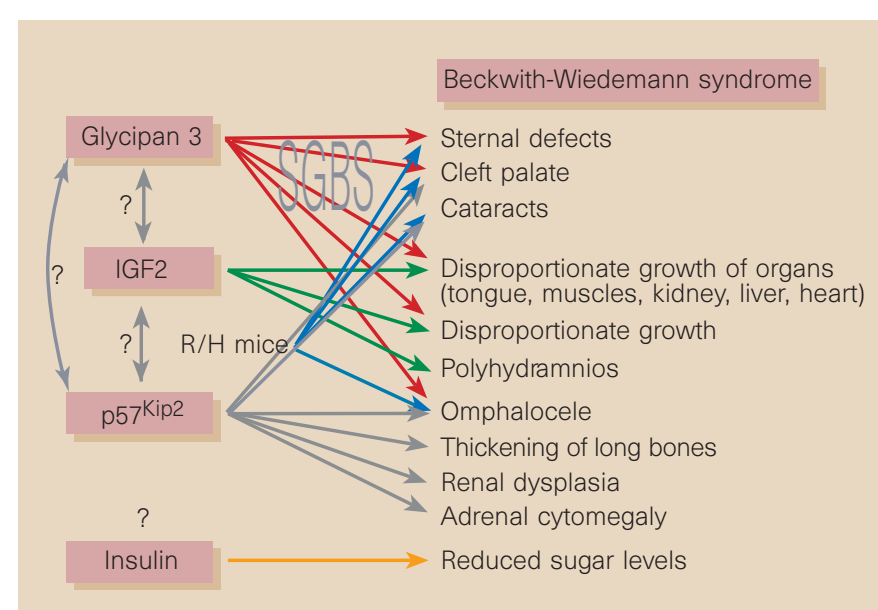

Figure 1 Clinical overlap and possible interactions between genes involved in Beckwith-Wiedemann syndrome and Simpson-GolabiBehmel syndrome (SGBS). Note that not all possible interactions may be shown.

an extra copy of the Igf 2 gene into embryonal stem cell lines. These cells were then mixed with normal embryos to make chimaeras. The chimaeras that expressed a 1.5-3-fold increase in Igf2 were overgrown, they had disproportionate overgrowth of the tissues that are normally affected in BWS, and polyhydramnios was associated with the pregnancy. In each case, there was an excellent correlation between the size of an organ and its level of Igf2 expression, supporting the idea that IGF2 may work at short range in the body.

But overexpression of IGF2 does not account for all of the BWS phenotypes what about omphalocele, adrenal cytomegaly, bone defects, renal dysplasia and hypoglycaemia (Fig. 1)? Most of these features can probably be explained by loss of activity of a second imprinted gene that encodes the cell-cycle regulator $\mathrm{p} 57^{\mathrm{Kip} 2}$. This protein inhibits the activity of cyclin-dependent kinases ${ }^{8,9}$, and it is expressed from the maternal gene copy on chromosome 11p15. Hence, paternal duplication with loss of the maternal chromosome would lead to the reduction or absence of $\mathrm{p} 57^{\text {Kip2 }}$ activity. Loss-of-function mutations in the $p 57^{\text {Kip2 }}$ gene have, in fact, been described in several people with BWS ${ }^{10-12}$. However, as these represent only $10 \%$ or so of cases, the general significance of this gene in BWS has been questioned.

In the case of $\mathrm{p} 57^{\mathrm{Kip} 2}$, clarity came from studying mice in which the gene was specifically disrupted $^{8,9}$. These mice developed omphalocele, renal dysplasia, adrenal cytomegaly and bone defects, but there was no disproportionate overgrowth or polyhydramnios. So, adding together the effects of IGF2 overexpression and p $57^{\text {Kip } 2}$ loss of function, we can account for most - but not all - BWS phenotypes. Neither mouse model showed reduced sugar levels. Perhaps this is explained by overexpression of a third gene, the insulin gene, which also maps to 11 p15 and maybe imprinted.

Is there any evidence for communication between the pathways involving IGF2 and $p 57^{\text {Kip2 }}$ ? Clues can be found from examina- tion of another mouse model that has just been produced by Eggenschwiler et al. ${ }^{13}$. Using a clever combination of genetic crosses, these authors created mice ( $\mathrm{R} / \mathrm{H}$ mice) with up to a sevenfold increase of Igf2 in their circulation. The $\mathrm{R} / \mathrm{H}$ mice died at varying stages during fetal development and never reached term. They were up to $200 \%$ of the normal body weight and, like the mice described by Sun et al. ${ }^{4}$, they had disproportionate overgrowth of certain organs. Like the $\mathrm{p} 57^{\mathrm{Kip} 2}$-mutant mice, the $\mathrm{R} / \mathrm{H}$ mice also had an omphalocele, one of the most consistent features of BWS. The two types of mutant mouse also shared three other phenotypes that are not usually considered part of BWS - cleft palate, cataracts and sternal defects. Notably, cleft palate and cataracts have now been documented in a small proportion of BWS patients, and these shared phenotypes indicate that there may be some crosstalk between the IGF2 and p $57^{\text {Kip2 }}$ pathways.

These mouse models also reinforce the possible mechanistic link between BWS and another human overgrowth syndrome, the Simpson-Golabi-Behmel syndrome $(\mathrm{SGBS})^{14}$. Children with SGBS have often been misdiagnosed as having BWS. Howev$\mathrm{er}$, SGBS is more severe, and $50 \%$ of affected babies die immediately before or after birth. Also, some of the phenotypes that are observed in SGBS are not found in BWS particularly defects of the sternum and vertebrae. SGBS arises through mutations in the glycipan 3 gene on the $\mathrm{X}$ chromosome ${ }^{15}$. A tantalizing claim was that glycipan 3 (which is a membrane proteoglycan) could bind IGF2, potentially reducing the effective concentration of IGF $2^{14}$. This would provide a satisfying explanation for the overlap of symptoms between the two syndromes, because loss of glycipan 3 function would lead to increased levels of IGF2. Although this idea lost favour when another group could not reproduce the IGF2-glycipan 3 interaction $^{16}$, the mouse models have again shed some light. The $\mathrm{R} / \mathrm{H}$ mice showed a number of SGBS-specific patterns, particularly sternal and vertebral defects ${ }^{13}$. Perhaps, after all, IGF2 and glycipan 3 interact either directly or indirectly.

In science, we are always hoping for the surprise result that will take us in new directions. Sun et al. ${ }^{4}$ were the beneficiaries of such an unexpected bonus. In the chimaeric mice that carried an additional copy of the Igf 2 gene, the increased RNA and protein were not expressed from the transgenic copies but, rather, from the endogenous chromosomal copies of Igf2. So perhaps DNA sequences in the transgene were binding to, and sequestering, proteins that normally repress expression of the chromosomal copies.

In summary, transgenic mice have helped to unravel the mechanisms of two complex human diseases ${ }^{5}$. The studies also provide new insights into the way pathways intersect, and into different mechanisms of gene regulation. Moreover, the follow-up studies should tell us a lot about how IGF2 is regulated, and even about the process of imprinting itself.

Nicholas Hastie is at the MRC Human Genetics Unit, Western General Hospital, Crewe Road, Edinburgh EH4 2XU, UK.

1. Henry, I. et al. Nature 351, 665-667 (1991).

2. Little, M., Van Heyningen, V. \& Hastie, N. Nature 351, 609-610 (1991).

3. Reik, W. \& Maher, E. R. Trends Genet. 13,330-335 (1997).

4. Sun, F.-L., Dean, W. L., Kelsey, G., Allen, N. D. \& Reik, W. Nature 389, 809-815 (1997).

5. Leighton, P. A., Ingram, R. S., Eggenschwiler, J., Efstratiadis A. \& Tilghman, S. M. Nature 375, 34-37 (1995).

6. DeChiara, T. M., Efstratiadis, A. \& Robertson, E. J. Nature 345, 78-81 (1990).

7. Weksberg, R., Shen, D. R., Fei, Y. L., Song, Q. L. \& Squire, J. Nature Genet. 5, 143-149 (1993).

8. Zhang, P. et al. Nature 387, 151-158 (1997).

9. Yan, Y., Frisen, J., Lee, M.-H., Masague, J. \& Barbacid, M. Genes Dev. 11, 973-983 (1997).

10. Hatada, I. et al. Nature Genet. 14, 171-173 (1996).

11. O'Keefe, D. et al. Am. J. Hum. Genet. 61, 295-303 (1997).

12. Lee, M. P. et al. Am. J. Hum. Genet. 61, 304-309 (1997).

13. Eggenschwiler, J. et al. Genes Dev. (in the press).

14. Weksberg, R., Squire, J. A. \& Templeton, D. M. Nature Genet. 12, 225-227 (1996).

15. Pilia, G. et al. Nature Genet. 12, 241-247 (1996).

16. Song, H. H., Shi, W. \& Filmus, J. J. Biol. Chem. 272, 7574-7577 (1997).

\section{Avoided object}

Readers who have not read the explanatory leading article (see Nature 389, 213; 1997) may have been bemused by the appearance over the past five weeks, and the disappearance this week, of the series under the above title by Cornelia Parker. That series was commissioned in collaboration with the Ruskin School of Art and Design at Oxford University and sponsored by Southern Arts and the Arts Council of England. A new series of articles on art and science begins this week on page 799 